\title{
Orange Peel Powder: A Potent Source of Fiber and Antioxidants for Functional Biscuits
}

\author{
Varsha Rani, Veenu Sangwan, Varsha Rani* and Partibha Malik \\ Department of Foods and Nutrition, CCS Haryana Agricultural University, Hisar, India \\ *Corresponding author
}

K e y w o r d s
Orange peel
powder, Fiber,
Antioxidants,
Biscuits, Sensory
acceptability

\section{A B S T R A C T}

Orange peel is a rich source of dietary fiber and antioxidants. In current life style scenario, people are becoming more aware of functional key ingredients and thus the demand of functional foods is increasing. This study was aimed to develop functional biscuits by incorporating orange peel powder $(5,10,15$ and 20\%). Oranges were washed thoroughly, peeled and the fruit peels were cut into small pieces and oven dried (50 $\pm 5 \mathrm{C})$ and ground to a fine powder. Developed biscuits were evaluated for sensory characteristics using 9-point hedonic scale. Biscuits were analysed for proximate composition, dietary fiber and antioxidants using standard methodology. Statistically data were analysed by OPSTAT software. The contents of total, insoluble and soluble dietary fibres, total polyphenols and radical scavenging activity were found to be significantly $(p \leq 0.05)$ higher in orange peel powder incorporated biscuits than control. Total, insoluble and soluble dietary fiber in orange peel powder supplemented biscuits ranged from 8.33 to $13.33 \%$, 5.43 to 7.36 and 2.82 to 6.00 per cent, respectively whereas contents of same in control biscuits were found to be $2.70,1.74$ and 0.95 per cent, respectively. Orange peel powder can be successfully utilized upto 20 per cent for the development of fiber and antioxidants rich functional biscuits without affecting sensory attributes.

\section{Introduction}

One of the major segments of food processing in India is baking industry. Baked products are most popular because of their easy availability, ready to eat convenience and long shelf life. Biscuit is the most commonly used as snacks by children and adults (Dhankar, 2013). Their increasing demand also provides a wider scope for their production, fortification and other nutritional improvement. The purpose of fortification is mainly to maintain the nutritional quality of the products, to keep adequate nutrient levels in order to correct or prevent specific nutritional deficiencies in the population from certain deficiencies, to increase the added nutritional value of a product from a 
commercial viewpoint and to provide certain technological functions in food processing (Dukwal, 2004). It has been found that citrus by-products, if utilized fully, could be major sources of phenolic compounds. The peels, in particular, are an abundant source of natural flavonoids, and contain higher amount of phenolics compared to the edible portions (Gorinstein et al., 2001). The contents of total phenolics in peels of lemons, oranges, and grapefruit were 15 per cent higher than those in the peeled fruits. Flavonoids in citrus are a major class of secondary metabolites. The peel contains the highest amount of flavonoids than other parts and those flavonoids present in citrus fruits belong to six peculiar classes according to their structure i.e. flavones, flavanones, flavonols, isoflavones, anthocyanidins and flavanols (Senevirathne et al., 2009). Now a days to improve the nutritional quality of bakery products, whole natural foods and their by products are becoming part of the bakery products which improve their quality and nutritional bioavailability in a cost-effective way. Report had shown that orange peels are rich in phenolic compounds, vitamins, minerals and dietary fiber with good antioxidant properties (Ajila et al., 2007; Omoba et al., 2015). Dietary fiber (DF), which is an important component of orange peel, is the indigestible portion of food derived from plant and it helps in the movement of food and waste efficiently through the digestive system (Tabernero et al., 2011).

\section{Materials and Methods}

Orange was acquired in bulk from the fruit market of Hisar. All other ingredients required for the development of bakery products were procured from the local market of Hisar. Oranges were washed thoroughly, peeled and the fruit peels were cut into small pieces and oven dried $(50 \pm 5 \mathrm{C})$. Dried peel was converted into fine powder form and packed in airtight plastic container for further use. Control biscuits were prepared using refined flour by creaming method. Refined flour was replaced with 5, 10, 15 and 20 per cent of orange peel powder in experimental biscuits.

Biscuits were organoleptically evaluated by 10 semi trained judges using 9-point hedonic scale. Average of scores for all sensory characteristics, viz., color, appearance, flavor, texture, taste was expressed in terms of overall acceptability..

\section{Nutritional evaluation}

Proximate composition i.e. moisture, protein, fat, crude fibre, ash were determined by employing the standard method of AOAC (2010). Total, soluble and insoluble dietary fiber constituents were determined by the enzymatic method given by Furda (1981). Finely ground sample were extracted with $80 \%$ methanol for determination of antioxidant activity. The concentration of total phenol of the methanolic extracts was determined by the Folin-Ciocalteau colorimetric method (Singleton et al., 1999). Phenols present in plant extract reacted with specific redox reagent (Folin-Ciocalteau reagent) to form blue chromophore constituted by a phosphotungstic phosphomolybdenum complex which was measured at $750 \mathrm{~nm}$. The antioxidant activity of the extracts, on the basis of the scavenging activity of the stable DPPH free radical, was determined by the method followed by BrandWilliams et al., (1995) as previously described by Tadhani et al., (2009).

\section{Statistical analysis}

The data obtained were subjected to analysis of variance in a complete randomized design by OPSTAT software developed by Sheoran 
and Pannu (1999). Mean, standard error and CD (critical difference) were calculated for analysis of data.

\section{Results and Discussion}

\section{Sensory acceptability}

The mean sensory scores given to control biscuits developed using 100 per cent refined flour were ranged from 8.60 to 9.00 for color, appearance, aroma, texture, taste and overall acceptability and these biscuits were adjudged as 'liked extremely'. With the increased level of fortification $(5,10,15$ and $20 \%)$ of orange peel powder in biscuits, a slight decrease in the scores was observed however, this decrease was not significant. The scores given to overall acceptability of orange peel powder incorporated biscuits ranged from 7.30 to 8.30 and as a result, these biscuits were adjudged between 'liked moderately' to 'liked very much' (Table 1).

\section{Nutritional evaluation}

Results presented in Table 2 indicated that moisture content in control biscuits was 2.30 per cent while that of Type-I, Type-II, TypeIII and Type IV biscuits ranged from 2.40 to 4.30 per cent. The protein and fat contents in control biscuits were 9.23 and 19.66 per cent, respectively which were decreased significantly at each level of inclusion of orange peel powder. The ash and crude fibre contents in refined flour (control) biscuits were 0.73 and 0.66 per cent, respectively which increased significantly $(P \leq 0.05)$ in all types (Type-I to Type-IV) of biscuits from 0.90 to 1.36 per cent and from 0.76 to 0.93 per cent, respectively as the level of incorporation of orange peel powder was increased in biscuit formulation.

\section{Dietary fibre}

Result presented in Table 3 showed that total and soluble dietary fibre content of refined flour biscuits was 2.70 and 0.95 per cent, respectively which was increased to 8.30 to 13.33 and 2.82 to 6.00 per cent in orange peel powder fortified biscuits. Maximum total and soluble dietary fibre was observed in Type-IV biscuits i.e. 13.33 and 6.00 per cent and minimum was 8.30 and 2.82 per cent in TypeI biscuits. Control biscuits contained 1.74 per cent of insoluble dietary fibre which was ranged from 5.43 to 7.36 per cent in orange peel powder fortified biscuits. There was a significant increase in the total, insoluble and soluble dietary fibre content of biscuits as the level of incorporation with orange peel powder increased from 5 to 20 per cent.

Table.1 Mean sensory scores of orange peel powder fortified biscuits

\begin{tabular}{|c|c|c|c|c|c|c|}
\hline Biscuits & Colour & Appearance & Aroma & Texture & Taste & $\begin{array}{c}\text { Overall } \\
\text { acceptability }\end{array}$ \\
\hline Control (WF 100\%) & $9.0 \pm 0.000$ & $8.7 \pm 0.153$ & $8.6 \pm 0.221$ & $8.6 \pm 0.221$ & $8.6 \pm 0.221$ & $8.7 \pm 0.163$ \\
\hline Type-I & $8.6 \pm 0.163$ & $8.5 \pm 0.167$ & $8.4 \pm 0.400$ & $7.7 \pm 0.300$ & $8.2 \pm 0.389$ & $8.3 \pm 0.284$ \\
\hline Type-II & $7.9 \pm 0 . .314$ & $7.8 \pm 0.291$ & $8.2 \pm 0.291$ & $7.4 \pm 0.306$ & $7.5 \pm 0.401$ & $7.8 \pm 0.321$ \\
\hline Type-III & $7.7 \pm 0.260$ & $7.4 \pm 0.371$ & $7.7 \pm 0.367$ & $7.4 \pm 0.340$ & $7.4 \pm 0.340$ & $7.5 \pm 0.336$ \\
\hline Type-IV & $7.5 \pm 0.307$ & $7.3 \pm 0.367$ & $7.8 \pm 0.416$ & $7.1 \pm 0.277$ & $7.0 \pm 0.394$ & $7.3 \pm 0.352$ \\
\hline
\end{tabular}

Values are mean \pm SE of ten observations

Type-I (95:5), Type-II (90:10) Type-III(85:15) Type-IV(80:20)

$\mathrm{RF}=$ Refined Flour, OPP $=$ Orange peel powder 
Table.2 Proximate composition of orange peel powder fortified biscuits (\%, on dry matter basis)

\begin{tabular}{|c|c|c|c|c|c|}
\hline Biscuits & Moisture* & Protein & Fat & Ash & $\begin{array}{l}\text { Crude } \\
\text { fibre }\end{array}$ \\
\hline $\begin{array}{c}\text { Control (RF } \\
100 \%)\end{array}$ & $2.30 \pm 0.058$ & $9.23 \pm 0.088$ & $19.66 \pm 0.882$ & $0.73 \pm 0.033$ & $0.66 \pm 0.033$ \\
\hline Type-I & $2.40 \pm 0.058$ & $8.73 \pm 0.240$ & $17.33 \pm 0.333$ & $0.90 \pm 0.058$ & $0.76 \pm 0.033$ \\
\hline Type-II & $5.53 \pm 0.120$ & $7.70 \pm 0.751$ & $16.33 \pm 0.333$ & $1.10 \pm 0.058$ & $0.81 \pm 0.017$ \\
\hline Type-III & $5.83 \pm 0.033$ & $7.43 \pm 0.884$ & $16.00 \pm 0.577$ & $1.30 \pm 0.058$ & $0.86 \pm 0.033$ \\
\hline Type-IV & $6.30 \pm 0.231$ & $7.36 \pm 0.928$ & $15.33 \pm 0.333$ & $1.36 \pm 0.033$ & $0.93 \pm 0.033$ \\
\hline$C D(p \leq 0.05)$ & 0.436 & 0.423 & 1.880 & 0.167 & 0.099 \\
\hline
\end{tabular}

Values are mean \pm SE of three independent determinations; RF $=$ Refined Flour Type-I (95:5), Type-II (90:10) Type-III (85:15) Type-IV (80:20) Orange peel powder

Table.3 Dietary fibre content of orange peel powder fortified biscuits (\%, on dry matter basis)

\begin{tabular}{|c|c|c|c|}
\hline \multirow[t]{2}{*}{ Biscuits } & \multicolumn{3}{|c|}{ Dietary fibre } \\
\hline & Total & Soluble & Insoluble \\
\hline Control (WF 100\%) & $2.70 \pm 0.058$ & $0.95 \pm 0.076$ & $1.74 \pm 0.031$ \\
\hline Type-I & $8.30 \pm 0.058$ & $2.82 \pm 0.065$ & $5.43 \pm 0.058$ \\
\hline Type-II & $9.66 \pm 0.088$ & $4.06 \pm 0.033$ & $5.60 \pm 0.058$ \\
\hline Type-III & $11.43 \pm 0.088$ & $5.00 \pm 0.058$ & $6.40 \pm 0.058$ \\
\hline Type-IV & $13.33 \pm 0.088$ & $6.00 \pm 0.058$ & $7.36 \pm 0.033$ \\
\hline $\mathrm{CD}(\mathrm{p} \leq 0.05)$ & 0.212 & 0.200 & 0.178 \\
\hline
\end{tabular}

Values are mean \pm SE of three independent determinations; RF $=$ Refined Flour

Type-I (95:5), Type-II (90:10) Type-III (85:15) Type-IV (80:20) Orange peel powder

Table.4 Anti-oxidant activity of orange peel powder fortified biscuits (\%, on dry matter basis)

\begin{tabular}{|c|c|c|}
\hline Biscuits & $\begin{array}{c}\text { Total phenols } \\
\text { (mgGAE/100gm) }\end{array}$ & $\begin{array}{c}\text { Antioxidant activity by } \\
\text { DPPH(mgTE/100gm }\end{array}$ \\
\hline Control (RF 100\%) & $65.19 \pm 0.37$ & $19.26 \pm 0.54$ \\
\hline Type-I & $100.73 \pm 0.55$ & $26.09 \pm 0.58$ \\
\hline Type-II & $136.66 \pm 0.64$ & $33.04 \pm 0.58$ \\
\hline Type-III & $172.40 \pm 1.16$ & $40.06 \pm 0.58$ \\
\hline Type-IV & $208.15 \pm 0.59$ & $46.69 \pm 0.35$ \\
\hline CD (p $\leq \mathbf{0 . 0 5})$ & 2.628 & 0.442 \\
\hline
\end{tabular}

Values are mean $\pm \mathrm{SE}$ of three independent determinations Type-I (95:5), Type-II (90:10) Type-III(85:15) Type-IV(80:20)

$\mathrm{RF}=$ Refined Flour, OPP $=$ Orange peel powder 
Plate.1 Orange peel powder fortified biscuits

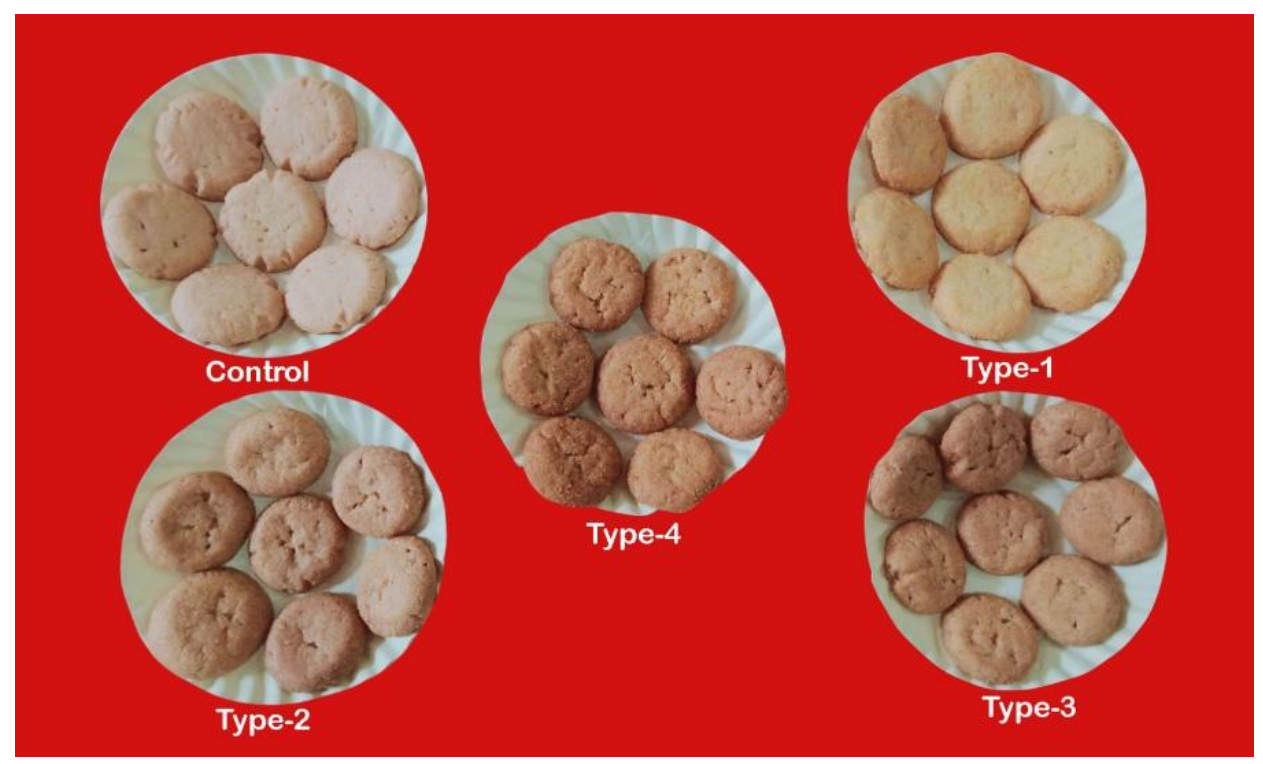

\section{Antioxidants}

Total phenols and DPPH radical scavenging activity of control and fortified biscuits has been presented in Table 4. Control biscuits had $165.19 \mathrm{mgGAE} / 100 \mathrm{~g}$ of total phenols and $19.26 \mathrm{mgTE} / 100 \mathrm{~g}$ of DPPH radical scavenging activity.

Total phenols and DPPH radical scavenging activity of orange peel powder fortified biscuits were significantly $(P \leq 0.05)$ higher than that of control biscuits. Type-I and TypeII biscuits contained polyphenols 100.73 and $136.66 \mathrm{mgGAE} / 100 \mathrm{~g}$, and radical scavenging activity was 26.09 and $33.04 \mathrm{mgTE} / 100 \mathrm{~g}$, respectively while Type-III and Type-IV value added biscuits contained polyphenols 172.40 and $208.15 \mathrm{mgGAE} / 100 \mathrm{~g}$, and radical scavenging activity 40.06 and 46.69mgTE/100g, respectively.

The mean score of overall acceptability of the control biscuits was 8.70 which fell in the category of "Liked extremely" whereas that of orange peel powder fortified biscuits varied from 8.3 (liked very much) to 7.3 (liked moderately). Results of sensory acceptability observed in present study are in close agreement with the findings of Kohajdova et al., (2011) and Nassar et al., (2008) who reported that orange peel powder supplemented biscuits scored less for sensory acceptability as compared to control, however these were acceptable. Citrus peel is rich in nutrients such as soluble sugars, proteins and minerals. It contained antioxidants such as flavonoids $(2.685 \pm 0.062 \mathrm{~g} / 100 \mathrm{~g})$ and vitamin C $(0.105 \pm 0.003 \mathrm{~g} / 100 \mathrm{~g})$. They also observed that orange peel powder fortified products contained less amounts of protein and fat as compared to control products. However the content of ash was higher in orange peel powder fortified products (Raj and Masih, 2012; Okpala et al., 2014; Hiri et al., 2015). Younis et al., (2016) developed cookies with different percentages of mosambi peel powder, 4, 6, 8, 10 and 12 per cent and observed that total dietary fibre as well as soluble and insoluble dietary fibre of cookies increased with increasing levels of mosambi peel powder in control formulation. The differences in the total anti-oxidant activity of control and orange peel powder fortified biscuits were due to higher contents of antioxidants present in orange peel powder. The 
results of present study are in agreement with those of other workers Awad et al., (2008) and Abd El-aal and Halaweish (2010).

From the present study, it may be concluded that fiber and antioxidants rich biscuits could be developed with incorporation of orange peel powder up to 20 per cent without compromising the sensory acceptable. The developed orange peel value added biscuits which were found to be rich in antioxidants, minerals and dietary fibres of all types should be commercialized and promoted so that of orange peels will be utilised which are otherwise going to waste. Such value added products also serve to manage the problem of malnutrition and hidden hunger among the population especially vulnerable groups. Development and consumption of such products also can help in improving the nutritional status of growing children.

\section{References}

Abd El-aal, H.A., and Halaweish, F.T. 2010. Food preservative activity of phenolic compounds in orange peel extracts (Citrus sinensis L.). Lucari stiintificeseria Zoothehnie, 53(15):233-240.

Ajila, C. M., Bhat, S. G., and Rao, U. P. 2007. Valuable components of raw and ripe peels from two Indian mango varieties. Food Chemistry, 102(4), 1006-1011.

AOAC. 2010. Official Method of Analysis. Association of official Analytical chemist. Washington, D.C.

Awad, A. M., Magda, R. A., and Selim, K. A. 2008. Evaluation of mandarin and navel orange peels as natural sources of antioxidant in biscuits. In Alex. J. Fd. Sci. \& Technol. Special Volume Conference (pp. 75-82).

Brand-Williams, W., Cuvelier, M.E. and Berset, C. 1995. Use of a free radical method to evaluate antioxidant activity. Lebensm. - Wiss. Technol. 28: 25-30.

Dhankhar, P., and Tech, M. 2013. A study on development of coconut based gluten free cookies. International Journal of Engineering Science Invention, 2(12), 10-19.

Dukwal, V. 2004. Fortification of Food for Value Addition: Prospects and Constraints. Department of Food and Nutrition College of Home Science Rajasthan Agricultural University Bikaner (Rajasthan).

Furda, I.1981. Simultaneous analysis of soluble and insoluble dietary fibre. In W.P.T. James, and O. Theander (Eds.), The Analysis of Dietary Fibre in food. Marcel dekker, New York. 163-172.

Gorinstein, S., Zachwieja, Z., Folta, M., Barton, H., Piotrowicz, J., Zemser, M. and Màrtín-Belloso, O. 2001. Comparative contents of dietary fiber, total phenolics, and minerals in persimmons and apples. Journal of agricultural and food chemistry, 49(2), 952-957.

Hiri N. M. H, Ioannou, I., Ghoul, M. And Mihoubi Boudhrioua, N. (2015) Proximate chemical composition of orange peel and variation of phenols and antioxidant activity during convective air drying, Journal of new sciences, (9): 2286-5314.

Kohajdova, Z., Karovicova, J., Jurasova, M., \& Kukurova, K. 2011. Application of citrus dietary fibre preparations in biscuit production. Journal of Food \& Nutrition Research, 50(3).

Lindsey, W.L. and Norwell, M.A. 1969. A new DPTA-TEA Soil test for zinc and iron. Agron. Abst. 61, 84-89.

Nassar, A.G., Abd-El-Hamied, A.A. and Naggar, E.1. 2008. Food Science and Technology Department, ALAzhar University, Assuit, Egypt. 
Okpala, L. C., and Akpu, M. N. 2014. Effect of Orange Peel Flour on the Quality Characteristics of Bread British Journal of Applied Science \& Technology, 4(5): 823-830

Omoba, O. S., Obafaye, R. O., Salawu, S. O., Boligon, A. A., and Athayde, M. L. 2015. HPLC-DAD phenolic characterization and antioxidant activities of ripe and unripe sweet orange peels. Antioxidants, 4(3), 498512.

Raj, A., and Masih, D. 2014. Physico chemical and rheological properties of wheat flour bun supplemented with orange peel powder. International Journal of Science and Research, 3(8), 391-394.

Senevirathne, M., Jeon, Y. J., Ha, J. H. and Kim, S. H. 2009. Effective drying of citrus by-product by high speed drying: A novel drying technique and their antioxidant activity. Journal of Food Engineering, 92(2): 157-163.

Sheroan, O.P. and Pannu, R.S. 1999. Statistical Package for agricultural workers. O.P. Stat College of
Agriculture, Kaul, CCS Haryana Agricultural University, Hisar. India

Singleton, V.L., Orthofer, R. LamuelaRaventos, R.M. 1999. Analysis of total phenols and other oxidation substrates and antioxidants by means of Folin-Ciocalteu reagent. Methods Enzymol. 299: 152-178.

Tabernero, M., Venema, K., Maathuis, A. J., and Saura-Calixto, F. D. 2011. Metabolite production during in vitro colonic fermentation of dietary fiber: analysis and comparison of two European diets. Journal of agricultural and food chemistry, 59(16), 89688975.

Tadhani, M.B., Patel, V.H. and Subhash, R. 2009. In vitro antioxidant activities of Stevia rebaidiana leaves and callus. J. of Food Compos. Analy. 20: 323-329

Younis, K., Islam, R., Jahan, K., Kundu, M., and Ray, A. 2016. Investigating the effect of mosambi (Citrus limetta) peel powder on physicochemical and sensory properties of cookies. Quality Assurance and Safety of Crops \& Foods, 8(3), 393-398.

\section{How to cite this article:}

Varsha Rani, Veenu Sangwan, Varsha Rani and Partibha Malik. 2020. Orange Peel Powder: A Potent Source of Fiber and Antioxidants for Functional Biscuits. Int.J.Curr.Microbiol.App.Sci. 9(09): 1319-1325. doi: https://doi.org/10.20546/ijcmas.2020.909.167 